\title{
Upgrading a Social Media Strategy to Increase Twitter Engagement During the Spring Annual Meeting of the American Society of Regional Anesthesia and Pain Medicine.
}

\author{
Eric S. Schwenk \\ Thomas Jefferson University \\ Kellie M. Jaremko \\ Thomas Jefferson University \\ Rajnish K. Gupta \\ Vanderbilt University Medical Center \\ Ankeet D. Udani \\ Pofkew University AdedtioalaYentaks at: https://jdc.jefferson.edu/anfp

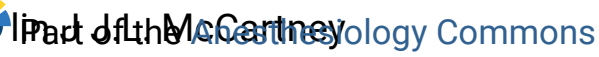 \\ universitys or Rtamer how access to this document benefits you
}

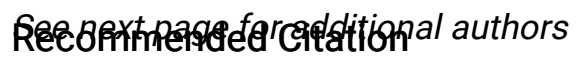

Schwenk, Eric S.; Jaremko, Kellie M.; Gupta, Rajnish K.; Udani, Ankeet D.; McCartney, Colin J J.L.; Snively, Anne; and Mariano, Edward R., "Upgrading a Social Media Strategy to Increase Twitter Engagement During the Spring Annual Meeting of the American Society of Regional Anesthesia and Pain Medicine." (2017). Department of Anesthesiology Faculty Papers. Paper 34.

https://jdc.jefferson.edu/anfp/34

This Article is brought to you for free and open access by the Jefferson Digital Commons. The Jefferson Digital Commons is a service of Thomas Jefferson University's Center for Teaching and Learning (CTL). The Commons is a showcase for Jefferson books and journals, peer-reviewed scholarly publications, unique historical collections from the University archives, and teaching tools. The Jefferson Digital Commons allows researchers and interested readers anywhere in the world to learn about and keep up to date with Jefferson scholarship. This article has been accepted for inclusion in Department of Anesthesiology Faculty Papers by an authorized administrator of the Jefferson Digital Commons. For more information, please contact: JeffersonDigitalCommons@jefferson.edu. 


\section{Authors}

Eric S. Schwenk, Kellie M. Jaremko, Rajnish K. Gupta, Ankeet D. Udani, Colin J J.L. McCartney, Anne Snively, and Edward R. Mariano 
Upgrading a Social Media Strategy to Increase Twitter Engagement during the Spring Annual Meeting of the American Society of Regional Anesthesia and Pain Medicine

\section{Corresponding Author:}

Eric S. Schwenk, MD

Sidney Kimmel Medical College at Thomas Jefferson University

Department of Anesthesiology

Suite 8130, Gibbon Building

111 South $11^{\text {th }}$ Street

Philadelphia, PA 19107

Phone: 215-955-6161

Fax: 215-955-0677

Email: Eric.Schwenk@jefferson.edu

\section{Co-Authors:}

Kellie M. Jaremko, MD, PhD

Thomas Jefferson University Hospital

Rajnish K. Gupta, MD

Vanderbilt University Medical Center

Ankeet D. Udani, MD, MSEd

Duke University Medical Center

Colin J.L. McCartney, MBChB, PhD, FRCA, FCARCSI, FRCPC

University of Ottawa

Anne Snively, MBA, CAE

American Society of Regional Anesthesia and Pain Medicine

Edward R. Mariano, MD, MAS

Stanford University School of Medicine

Institutional Affiliation of Manuscript:

Sidney Kimmel Medical College at Thomas Jefferson University

\section{Sources of Funding:}

None

Conflicts of Interest: Dr. Mariano has received unrestricted educational program funding paid to his institution from Halyard Health (Alpharetta, GA, USA) and B Braun (Bethlehem, PA, USA). These companies had no input into any aspect of the present study design and implementation; data collection, analysis and interpretation; or manuscript preparation.

All other authors have no conflicts of interest to declare. 
Page 2 of 24

Short Running Title: Twitter Use at the Spring ASRA Meetings

Word Count: 3,081 


\section{Abstract (unstructured)}

2 Microblogs known as Tweets are a rapid, effective method of information dissemination in

3 healthcare. Although several medical specialties have described their Twitter conference

4 experiences, few data exist in the fields of anesthesiology and pain medicine. We therefore

5 analyzed the Twitter content of two consecutive Spring meetings of the American Society of

6 Regional Anesthesia and Pain Medicine using publicly available online transcripts. We also

7 examined the potential contribution of a targeted social media campaign on Twitter engagement

8 during the conferences. The original Twitter meeting content was largely scientific in nature and

9 created by meeting attendees, the majority of whom were non-trainee physicians. Physician

10 trainees, however, represent an important and increasing minority of Twitter contributors.

11 Physicians not in attendance predominantly contributed via retweeting original content,

12 particularly picture-containing Tweets, and thus increased reach to non-attendees. A social media

13 campaign prior to meetings may help increase the reach of conference-related Twitter discussion. 


\section{Introduction}

3 Twitter, an online social media platform launched in 2006 and based in San Francisco, CA,

4 allows its users to post "micro-blogs" of 140 characters or less (referred to as "Tweets"). ${ }^{1}$ Its use

5 in healthcare has led to the ability of physicians, nurses, and other healthcare professionals to

6 rapidly communicate health-related education and information in a public venue. Twitter users

7 can engage in international conversations by including "hashtags" (a meeting code or keyword

8 starting with the \# symbol) in their Tweets which allow grouping based on topic and ability to be

9 searched. The use of social media, specifically Twitter, in national medical meetings has

10 increased in recent years, and several medical specialties have described their experiences. ${ }^{2-6}$

11 Twitter has become the preferred platform for scientific meetings over other platforms such as

12 Facebook likely due to advantages like short-form messaging, easily grouped themes with

13 hashtags, and rapid spread of messages ("going viral") with easy sharing through "Retweeting."

14 However, very little has been published on Twitter use within the medical specialties of

15 anesthesiology and pain medicine, ${ }^{7,8}$ therefore, the benefits in enhancing the conference

16 experience, if any, remain unknown. In addition, methods to increase public interest and

17 engagement on topics presented at scientific conferences have not been previously studied.

19 The Spring annual meeting of the American Society of Regional Anesthesia and Pain Medicine

20 (ASRA) has been held for the past 41 years and consists of 3-4 days of lectures, workshops,

21 problem-based learning discussions, and other interactive events dedicated to the subspecialty of

22 regional anesthesiology and acute pain medicine. Twitter hashtags for these meetings are

23 registered with Symplur (Upland, CA), a healthcare social media analytics company, annually 
1 prior to each conference. The purpose of this study is to describe the Twitter-based conference

2 discussions at the ASRA Spring 2015 and 2016 annual meetings and to quantify the effects of a 3 targeted social media strategy launched in between the two meetings. 
10 in advance of each meeting.

11

\section{Social Media Engagement Strategy}

13 Prior to the Spring 2015 ASRA meeting (the $40^{\text {th }}$ annual Regional Anesthesiology and Acute

14 Pain Medicine Meeting) in Las Vegas, NV, there was no targeted social media engagement

15 strategy. Advertisements for the meeting, including reminders for registration and abstract

16 submission deadlines, were posted on the society's social media platforms (e.g., Facebook,

17 LinkedIn, and Twitter) primarily for marketing and not including the meeting hashtag. Starting

18 two months prior to the meeting, emails from the ASRA office encouraged ASRA members and 19 attendees to "Follow and tweet using \#ASRASpring15 now and throughout the conference" or

20 provided "Suggested Tweets/Posts" such as: "Have you submitted your video for the Interactive

21 \#RegionalAnesthesia session at \#ASRASpring15 yet?" No specific meeting attendees or

22 presenters with social media accounts were mentioned on the website or in any emails about the 23 meeting. 
2 Before the Spring 2016 ASRA meeting (the $41^{\text {st }}$ annual Regional Anesthesiology and Acute Pain

3 Medicine Meeting), the meeting hashtag \#ASRA_RA16 was circulated in emails from the ASRA

4 office and other marketing communications more than 6 months in advance. Through its website,

5 ASRA introduced its first "Social Media Team" with a unique web page

6 (https://www.asra.com/page/242/social-media) to encourage members and meeting attendees to

7 join Twitter and promote social media engagement prior to and during the meeting. This page

8 featured photographs, short biographies, and Twitter handles of nine ASRA members who were

9 regular users of Twitter (https://www.asra.com/page/242/social-media). All ASRA members

10 received emails about the creation of the Social Media Team in November and December 2015.

11 At the conference hotel in New Orleans, LA, several large signs encouraged members to use

12 Twitter and featured the conference hashtag \#ASRA_RA16. A comparison of the social media

13 strategies employed at the two meetings is shown in Table 1.

15 Measurements

16 The time period for analysis of Tweets started at the time of on-site registration opening on the

17 first day for the Spring 2015 meeting in Las Vegas, NV, May 14, 2015 at 4:00 A.M. (PDT), and

18 ended at 5:30 P.M. (PDT) on May 16, 2015, the last day of the conference. The same time

19 interval was used for the Spring 2016 meeting in New Orleans, LA, which began on March 31,

20 2016, and ended on April 2, 2015. Time was adjusted for the time zone of the city in which each

21 meeting was held. From Symplur, we obtained summary measurements of Twitter productivity

22 and engagement: total number of impressions, total number of Tweets, total number of

23 participants on Twitter, average number of Tweets per hour, average number of Tweets per 
1 participant, top 10 Twitter participants by mention, top 10 Twitter participants by number of

2 Tweets, and top 10 Twitter participants by impressions. Symplur defines impressions as "taking

3 the number of tweets per participant and multiplying it with the number of followers that

4 participant currently has." ${ }^{, 9}$ Impressions serve as a measure of the overall audience that the tweets

5 have. Demographics, society membership status, and other characteristics of meeting attendees

6 were collected from the ASRA meeting registration database and matched with the Twitter

7 transcripts obtained from Symplur. Each retweet (RT) was analyzed and cross-referenced with

8 the list of meeting registrants and attendees. The inclusion of pictures within Tweets was

9 recorded.

\section{Classification of Tweets}

12 Twitter transcripts were converted to PDF format for review, and all Tweets were analyzed by

13 two investigators, ESS and KMJ, independently. Tweets were assigned to one of four categories:

14 scientific, logistical, social, or other, based on a slightly modified classification system described

15 by Attai et $\mathrm{al}^{2}$ and Awad et al. ${ }^{10}$ "Scientific" Tweets were defined as those that contained

16 education-related to a specific topic from a meeting session or a scientific or medical topic that

17 had some connection to the meeting. "Logistical" Tweets were those related to locations of

18 sessions, timing, or session details other than content, and any informational Tweet or

19 announcement about the location of a particular session or event at the meeting. "Social" Tweets

20 were those containing general impressions of the meeting or venue, sightseeing, jokes or other

21 banter, or discussion of activities that occurred outside of meeting locations, including future

22 meetings or events. "Other" referred to any Tweet that did not obviously fall into one of the

23 other three categories. Each category was given a priority ranking (1-4 out of 4 with 1 being the 
1 highest) based on relevance to meeting content: scientific (rank 1), logistical (rank 2), social

2 (rank 3), and other (rank 4). Tweets that could have fit into more than one category were

3 categorized by the category with highest priority (i.e., a Tweet with scientific and social content

4 would be classified as scientific, for example, because scientific is higher priority than social).

5 Tweets were also described in terms of type of Tweet, as defined by Twitter designations:

6 original, reply, modified RT, or unmodified RT. Inter-rater reliability for Tweet category

7 assignments was determined by calculating the intra-class correlation coefficient (ICC). For the

8 purposes of graphical representation, each Tweet could only have one category; therefore, any

9 disputes between the two primary raters were resolved by a third investigator, ADU, who was

10 blinded to the identities of the raters and their category selections for a given Tweet.

\section{Statistical Analysis}

13 ICC measurements were calculated for the two independent reviewers of Tweet categories.

14 Given the categorical nature of most of the data, analyses were performed using the chi square

$15\left(\mathrm{X}^{2}\right)$ test or nominal by nominal contingency coefficients when there were greater than two

16 categories per variable (e.g., type of Twitter engagement, Twitter participant category).

17 Normality of distribution was determined for all scale variables. Single comparisons of

18 independent variables were performed using Mann-Whitney $U$ test for continuous data in non-

19 normal distributions. All analyses were performed using SPSS software (Version 23.0, Armonk,

20 NY). A two-sided $\mathrm{p}<0.05$ was considered statistically significant. 


\section{Results}

3 The number of conference registrants decreased by 154 people from 2015 to 2016 . The

4 demographics of attendees at the ASRA Spring annual meetings shifted slightly between

5 categories from 2015 to 2016 but the overall order did not change, with physician ASRA

6 members being the largest group, followed by trainee ASRA members, trainee non-ASRA

7 members, and physician non-ASRA members (Table 2). The number of overall Twitter

8 participants increased from 160 in 2015 to 209 in 2016 with identifiable individual participants

9 similarly increasing from 102 to 131 . The number of original Tweets (excluding unmodified

10 RTs) increased from 379 to $658(73.6 \%)$ with the number of impressions increasing from

11664,335 to $1,460,008$ (120\%; Table 3). Discussion between Twitter participants was evaluated

12 using number of "replies" as a surrogate marker, which showed a significant increase in number

13 and percentage of original tweets between $2015(\mathrm{n}=26,6.9 \%)$ and $2016(\mathrm{n}=83,12.6 \% ; \mathrm{p}<$

14 0.001). The type of Twitter engagement (original Tweets, unmodified RTs only, or both) was

15 strongly associated with meeting attendance $(\mathrm{p}<0.001$; Figure 1$)$ with those who created

16 original content more likely to have attended and those who retweeted only more likely to have

17 not. The top 10 Twitter accounts based on number of impressions generated are shown in Table 184.

20 Analysis of Tweets by individuals (groups and unknown accounts excluded) revealed that for the

21 Spring 2015 meeting 331/340 total Tweets (97.4\%) were by attendees with 9/340 (2.6\%) by non-

22 attendees versus 546/576 total (94.8\%) by meeting attendees with 30/576 (5.2\%) by non-

23 attendees for Spring $2016(\mathrm{p}=0.102)$. The majority of participants in the Twitter feed, including 
1 those who only retweeted original content (60.6\% in 2015 and $58.8 \%$ in 2016), did not attend the

2 meeting. When comparing Tweets by physicians at both meetings, $317 / 379(83.6 \%)$ were created

3 by physicians at Spring 2015 versus 497/658 (75.5\%) at Spring 2016 ( $\mathrm{p}<0.001)$. However,

4 Tweets by trainees increased from $13 / 379(3.4 \%)$ in 2015 to $74 / 658(11.2 \%)$ in 2016 (p < 0.001$)$.

5

6 In 2015, 39\% of original Tweets contained a picture; this percentage decreased to $31 \%$ in 2016

7 despite an overall increased number of picture-containing tweets (148 in 2015 to 203 in 2016; p

$8=0.008$ ). The average number of RTs per original Tweet that contained pictures increased from

$9 \quad 1.5$ in 2015 to 2.1 in 2016. There was a statistically significant increase in likelihood of an

10 original Tweet being retweeted if it contained pictures in $2016(\mathrm{p}<0.001)$ but not in 2015 . The

11 top 10 participants in order of the number of times their Tweets were retweeted are shown in

12 Table 5.

13

14 Figures $2 \mathrm{a}$ and $2 \mathrm{~b}$ show the distribution of Tweets by content category from the Spring 2015 and

15 Spring 2016 meetings. Scientific Tweets made up the majority with 292/379 (77\%) in Spring

162015 and 480/658 (73\%) in Spring $2016(\mathrm{p}=0.145)$ while social Tweets represented $14 \%$ of

17 Tweets from both meetings. Logistical and "other" Tweets formed the minority for both

18 meetings. One Tweet from each meeting was unable to be classified: from Spring 2015, one

19 Tweet was partially scientific but promotional for one specific company; and from Spring 2016,

20 one Tweet was both social and logistical. The ICC for Tweet category assignment between the

21 two raters for the Spring 2015 meeting was 0.82 and for the Spring 2016 meeting was 0.84. 
Page 12 of 24

1 Screen shots of a scientific Tweet and responses and a social Tweet are shown in Figures 3a and

$23 b$, respectively. 


\section{Discussion}

3 Our findings demonstrate that Twitter use contributes to the scientific discussion and overall

4 experience at the annual Spring ASRA meeting for both attendees and those following the

5 meeting from home. In addition, a targeted social media engagement strategy including a

6 dedicated Social Media Team may have led to an increase in total number of Tweets and

7 impressions from the Spring 2015 to the Spring 2016 meeting, despite a decrease in the number

8 of meeting attendees. We anticipate that the benefits of this relatively simple and inexpensive

9 strategy may become more relevant as social media use continues to grow amongst healthcare

10 professionals.

12 Consistent with the results of previous investigations in other medical specialties, ${ }^{2,3,5}$ our analysis

13 reveals that the large majority of Tweets at the ASRA Spring annual meeting are scientific

14 (meeting-related) in nature. This is important for several reasons. First, it suggests that the

15 majority of time spent on Twitter is used to disseminate meeting-related content; therefore

16 Twitter use during meeting time focuses participants on, rather than distracts from, important

17 content. Second, it demonstrates that Twitter does indeed contribute to the scientific discussion

18 at the meeting, and the number of RTs by non-attendees tells us that the discussion extends

19 beyond the meeting. The increase in the number of replies from 2015 to 2016 suggests followers

20 of the discussion are increasingly engaged. One interesting finding was that the majority of

21 Twitter participants from both meetings were non-attendees, who tended to retweet meeting

22 information. This is consistent with the findings of others. ${ }^{9}$ This speaks clearly to the external

23 reach of Twitter, highlights the importance of engaging those who cannot attend, and suggests 
1 that Twitter is an ideal platform for these types of social media-enhanced conferences. For

2 planners of continuing medical education events, the number of impressions through Twitter

3 may be a useful metric to track when determining which topics and/or speakers generate the

4 most public interest, are most current, and are most relevant.

6 Although logistical Tweets represented only 4\% and 7\% of Tweets in 2015 and 2016,

7 respectively, they represent a potential future opportunity. Because of the large number of

8 followers of the official ASRA Twitter handle, @ASRA_Society, (5,194 followers at the time of

9 this writing) and the increased attention during meeting times, Tweeting information about

10 upcoming sessions or speakers may attract prospective attendees for future conferences who may

11 otherwise not attend. In 2015, the official account only sent nine Tweets and in 2016 only sent

12 two. However, a balance must be struck between logistical Tweets from the official society

13 account and those by individual users. We speculate that too many Tweets by @ ASRA_Society

14 may be viewed as self-serving or promotional, but the "right" amount is not known. Our results

15 also suggest that Twitter participants enjoy Tweets with pictures included and are more likely to

16 share them with their followers.

18 Our finding that the number of impressions and overall engagement following a targeted social 19 media campaign increased warrants additional study. The doubling of the number of impressions

20 while having a decrease in meeting registration can be largely explained by the increase in the

21 number of Tweets and RTs by those who did participate. The number of Twitter participants

22 increased as well. We believe that the efforts of ASRA prior to the meeting are most likely the

23 major factor contributing to this change. Three of the top 10 Twitter influencers were featured on 
1 the ASRA Social Media Team webpage, and four of the top 10 Tweeters were featured there.

2 The increased attention given to these particular Twitter users for the Spring 16 meeting may

3 have encouraged them to increase their Tweet activity. In addition, direct promotion of specific

4 Twitter accounts may have led to an increase in the number of followers for each of these users,

5 thereby leading to the increase in impressions in Spring 2016 as their Tweets were able to reach

6 larger audiences. As Table 5 shows, the number of Retweets of original content dramatically

7 increased in Spring 2016. Some of this was due to the authors of this paper but clearly not all, as

8 five out of the top 10 participants by Retweets were not authors of this paper, including the

9 participant with the highest number of Retweets.

11 One interesting finding was that the percentage of physician Tweets decreased from 2015 to

12 2016. This occurred as the total number of Tweets increased, and an opportunity to reverse this

13 trend may exist in the contribution of physician trainees to the social media discussion at

14 meetings. The greater than three-fold increase in physician trainee representation in the Twitter

15 discussion from 2015 to 2016 supports the notion that younger members of the medical

16 community play an important role in social media and are actively involved in dissemination of

17 scientific information. Inclusion of physician trainees in future targeted social media campaigns

18 may be a high-yield means of enhancing meeting engagement that should not be overlooked.

20 Our study does have limitations. First, we only included Tweets that used the official meeting

21 hashtags and therefore Tweets that did not include it or misspelled it were not analyzed. Second,

22 classifying Tweets is inherently subjective. We tried to minimize this by using previously

23 published criteria and demonstrating strong inter-rater reliability. We also included a third 
1 reviewer to break any ties when summarizing Tweet categories for graphical representation, but

2 there can be difficulty in determining meaning in such succinct microblogs. Further, although we

3 believe that the ASRA social media promotion strategy affected Twitter activity and

4 impressions, we cannot establish a causal link based on this study. Other factors, such as the

5 natural increase in followers that some of the most active Tweeters had between meetings and

6 the general trend of increased social media use over time, may have also played a role in the

7 large increase in impressions. Finally, we cannot determine whether or not impressions indicate a

8 measure of knowledge translation and implementation of clinical practice change. An article by

9 Cabana and colleagues suggests that there are seven barriers to change: lack of awareness; lack

10 of familiarity; lack of agreement; lack of self-efficacy; lack of outcome expectancy; inertia; and

11 external factors. ${ }^{11}$ Although we cannot measure knowledge translation directly, we believe that

12 using Twitter during medical conferences may help address the barriers of lack of awareness and

13 familiarity when it comes to dissemination of scientific evidence.

15 In conclusion, the use of Twitter at the annual Spring meetings of ASRA contributes to the

16 scientific discussion and meeting experience for both attendees and non-attendees who seem to

17 participate in different ways. Although the majority of Twitter content remains scientific,

18 logistical Tweets may represent an area of potential growth in attracting attendees to specific

19 sessions or perhaps attracting prospective meeting attendees in the future. A targeted effort

20 before the 2016 meeting to highlight ASRA members active on Twitter may have contributed to

21 a dramatic increase in the number of Tweets and impressions created from the meeting and

22 warrants further study. 


\section{References}

1. Ekins S, Perlstein EO. Ten simple rules of live tweeting at scientific conferences. PLoS Comput Biol 2014;10:e1003789

2. Attai DJ, Radford DM, Cowher MS: Tweeting the Meeting. Twitter Use at The American Society of Breast Surgeons Annual Meeting 2013-2016. Ann Surg Oncol 2016;23:3418-22

3. Borgmann H, Woelm JH, Merseburger A, Nestler T, Salem J, Brandt MP, Haferkamp A, Loeb S. Qualitative Twitter analysis of participants, tweet strategies, and tweet content at a major urologic conference. Can Urol Assoc J 2016;10:39-44

4. Cochran A, Kao LS, Gusani NJ, Suliburk JW, Nwomeh BC. Use of Twitter to document the 2013 Academic Surgical Congress. J Surg Res 2014;190:36-40

5. Hawkins CM, Duszak R, Rawson JV. Social media in radiology: early trends in Twitter microblogging at radiology's largest international meeting. J Am Coll Radiol 2014;11:38790

6. Udovicich C, Barberi A, Perera K. Tweeting the meeting: A comparative analysis of an Australian emergency medicine conference over four years. J Emerg Trauma Shock 2016;9:28-31

7. McKendrick DR. Smartphones, Twitter and new learning opportunities at anaesthetic conferences. Anaesthesia 2012;67:438-9

8. Udani AD, Moyse D, Peery CA, Taekman JM. Twitter-Augmented Journal Club: Educational Engagement and Experience So Far. A A Case Rep 2016;6:253-6

9. Awad NI, Cocchio C. Use of Twitter at a major national pharmacy conference. Am J Health Syst Pharm 2015;72:65-9 
10. Utengen A. New Healthcare Analytics Features for Social Media. Symplur Healthcare Hashtags Project website. Available at: http://www.symplur.com/shorts/new-healthcareanalytics-features-social-media/. June 26, 2012. Accessed October 27, 2016.

11. Cabana MD, Rand CS, Powe NR, Wu AW, Wilson MH, Abboud PA, Rubin HR: Why don't physicians follow clinical practice guidelines? A framework for improvement. JAMA $1999 ; 282: 1458-65$ 
Table 1. Comparison of social media strategies employed for the spring 2015 and 2016 meetings.

\begin{tabular}{|l|c|c|}
\hline Activity & Spring 2015 & Spring 2016 \\
\hline $\begin{array}{l}\text { Emails sent to members prior to meeting with } \\
\text { meeting hashtag (\#) }\end{array}$ & Yes & Yes \\
\hline $\begin{array}{l}\text { Number of months prior to meeting when } \\
\text { hashtag was emailed to members }\end{array}$ & 2.5 & 4.5 \\
\hline Social Media Website created prior to meeting & No & Yes \\
\hline $\begin{array}{l}\text { Specific society members who use Twitter } \\
\text { promoted prior to meeting }\end{array}$ & No & Yes \\
\hline $\begin{array}{l}\text { Society members notified about a social media } \\
\text { team prior to meeting }\end{array}$ & No & Yes \\
\hline $\begin{array}{l}\text { Meeting hashtag (\#) featured on large poster at } \\
\text { meeting location in registration area }\end{array}$ & No & Yes \\
\hline
\end{tabular}


Table 2. Number and characteristics of meeting registrants.

\begin{tabular}{|l|c|c|}
\hline & \#ASRASpring15 & \#ASRA_RA16 \\
\hline Total Meeting Registrants & 1170 & 1016 \\
\hline Non-U.S. Registrants & $200(17.1 \%)$ & $100(9.8 \%)$ \\
\hline Number of Countries & $38(3.2 \%)$ & $31(3.1 \%)$ \\
\hline Number of US States & $48(4.1 \%)$ & $49(4.8 \%)$ \\
\hline Physician ASRA Member & $408(34.9 \%)$ & $330(32.5 \%)$ \\
\hline $\begin{array}{l}\text { Physician Member of } \\
\text { Partner Society }\end{array}$ & $16(1.4 \%)$ & $212(20.9 \%)$ \\
\hline Physician Non-Member & $67(5.7 \%)$ & $51(5.0 \%)$ \\
\hline Trainee ASRA Member & $193(16.5 \%)$ & $2(0.2 \%)$ \\
\hline Trainee Non-Member & $110(9.4 \%)$ & $14(1.4 \%)$ \\
\hline NP-PA & $12(1.0 \%)$ & $31(3.1 \%)$ \\
\hline Military & $9(0.8 \%)$ & $15(1.5 \%)$ \\
\hline Other & $31(2.6 \%)$ & $167(16.4 \%)$ \\
\hline Day rate & $13(1.1 \%)$ & $81(8.0 \%)$ \\
\hline Exhibitor & $169(14.4 \%)$ & \\
\hline Faculty & $87.4 \%)$ & \\
\hline Anesthesia and Pain Medicine; NP=Nurse Practitioner; PA=Physician Assistant. \\
\hline
\end{tabular}


Table 3. Summary of Twitter analytics.

\begin{tabular}{|c|c|c|}
\hline & \#ASRASpring15 & \#ASRA_RA16 \\
\hline Total Impressions ${ }^{\mathbf{a}}$ & 664,335 & $1,460,008$ \\
\hline Total Tweets & 811 & 1519 \\
\hline Original Tweets $^{\mathrm{b}}$ & 379 & 658 \\
\hline Unmodified Retweets & 432 & 861 \\
\hline Participants & 160 & 209 \\
\hline Average Tweets/Hour & 12 & 25 \\
\hline Average Tweets/Participant & 5 & 7 \\
\hline \multicolumn{3}{|c|}{$\begin{array}{l}\text { Data are presented as counts unless otherwise specified. } \\
\text { a. Impressions are defined by Symplur as "taking the number of Tweets per participant and } \\
\text { multiplying it with the number of followers that participant currently has." This included } \\
\text { unmodified retweets in the calculation. } \\
\text { b. Includes original Tweets and modified retweets. Retweets that were not modified were not } \\
\text { included in this count. }\end{array}$} \\
\hline
\end{tabular}


Table 4. Top 10 Twitter influencers by impressions.

\begin{tabular}{|c|c|c|}
\hline & \#ASRASpring15 & \#ASRA_RA16 \\
\hline 1 & $\begin{array}{c}\text { Olivier Branford } \\
\text { @OlivierBranford }\end{array}$ & $\begin{array}{c}\text { Amit Pawa } \\
\text { @ Amit_Pawa }\end{array}$ \\
\hline 2 & $\begin{array}{l}\text { Edward Mariano } \\
\text { @EMARIANOMD }\end{array}$ & $\begin{array}{l}\text { Kellie Jaremko } \\
\text { @ Neuro_Kellie }\end{array}$ \\
\hline 3 & $\begin{array}{l}\text { Matt McCord } \\
\text { @ MattMD }\end{array}$ & $\begin{array}{c}\text { Edward Mariano } \\
\text { @EMARIANOMD }\end{array}$ \\
\hline 4 & $\begin{array}{c}\text { Amit Pawa } \\
\text { @Amit_Pawa }\end{array}$ & $\begin{array}{l}\text { Duke Anesthesiology } \\
\text { @ Duke_Anesthesia }\end{array}$ \\
\hline 5 & $\begin{array}{l}\text { Minh Le Cong } \\
\text { @ ketaminh }\end{array}$ & $\begin{array}{l}\text { The ScientifiK } \\
@ \text { TheScientifiK }\end{array}$ \\
\hline 6 & $\begin{array}{l}\text { The ScientifiK } \\
\text { @ TheScientifiK }\end{array}$ & $\begin{array}{l}\text { Minh Le Cong } \\
\text { @ ketaminh }\end{array}$ \\
\hline 7 & $\begin{array}{c}\text { ASRA } \\
\text { @ ASRA_Society }\end{array}$ & $\begin{array}{c}\text { Kariem } \\
\text { @elboghdadly }\end{array}$ \\
\hline 8 & $\begin{array}{c}\text { Colin McCartney } \\
\text { @ ColinJMcCartney }\end{array}$ & $\begin{array}{c}\text { ASRA } \\
\text { @ ASRA_Society }\end{array}$ \\
\hline 9 & $\begin{array}{c}\text { Symplur } \\
\text { @ healthhashtags }\end{array}$ & $\begin{array}{c}\text { Raj Gupta } \\
\text { @Dr_RajGupta }\end{array}$ \\
\hline 10 & $\begin{array}{c}\text { Anesthesiology News } \\
@ \text { anesthesianews }\end{array}$ & $\begin{array}{c}\text { Symplur } \\
\text { @ healthhashtags }\end{array}$ \\
\hline
\end{tabular}


Table 5. Top 10 Twitter participants by number of Retweets.

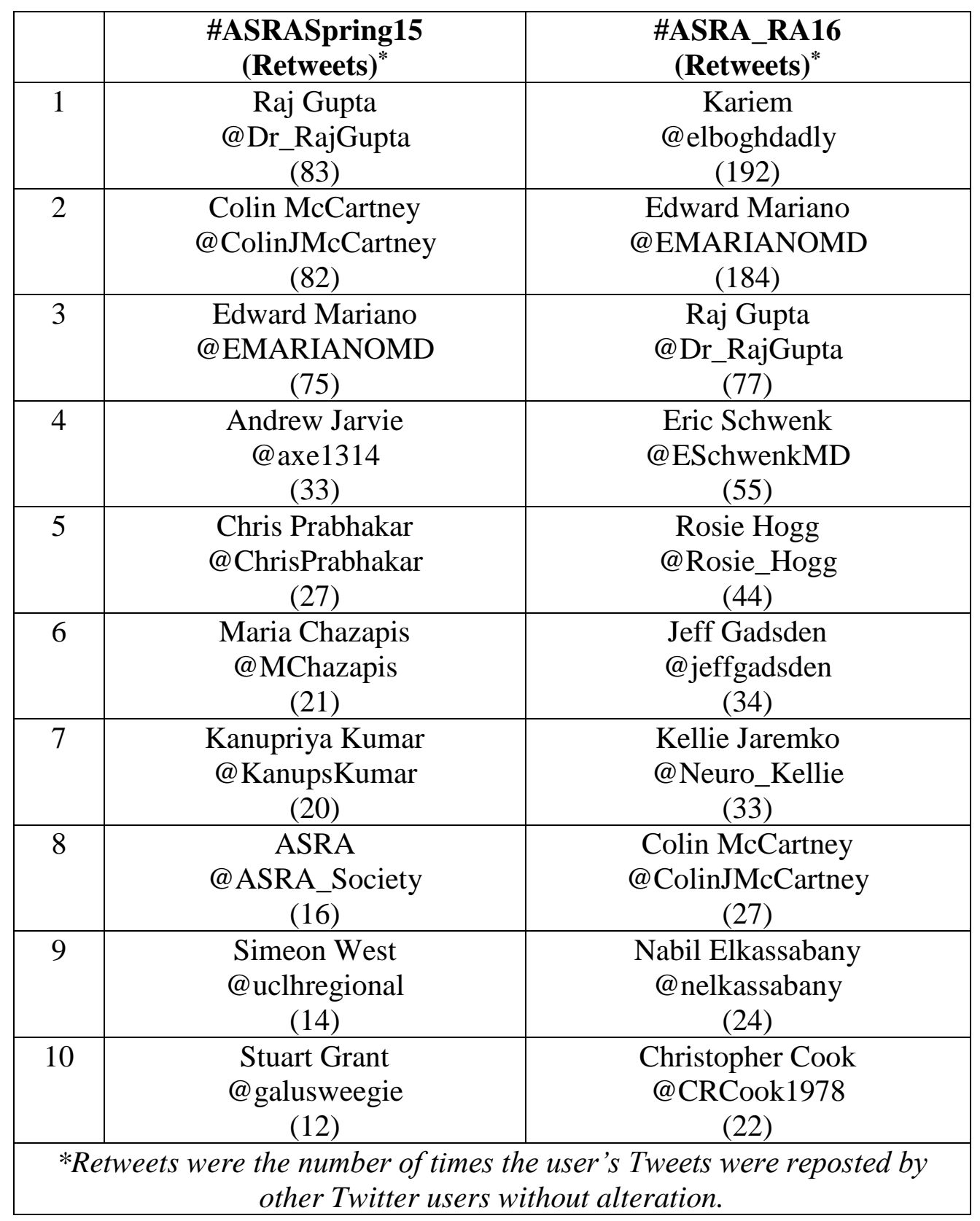




\section{Figure Legends}

Figure 1. Patterns of Twitter engagement categorized by participants' meeting attendance status.

Figures 2a and 2b. Tweet categories at the 2015 and 2016 Spring meetings of the American Society of Regional Anesthesia and Pain Medicine.

Figure 3a. Screen shots of a "scientific" Tweet and replies from the Spring 2016 meeting.

Figure 3b. Screen shot of a "social" Tweet from the Spring 2016 meeting. 